\title{
Factors affecting fruit and vegetable school lunch waste in Wisconsin elementary schools participating in Farm to School programmes
}

\author{
Andrea B Bontrager Yoder*, Leah L Foecke and Dale A Schoeller \\ Department of Nutritional Sciences, University of Wisconsin-Madison, 1415 Linden Drive, Madison, \\ WI 53706, USA
}

Submitted 30 May 2014: Final revision received 11 December 2014: Accepted 12 January 2015: First published online 2 March 2015

\begin{abstract}
Objective: To examine characteristics potentially associated with school lunch fruit and vegetable waste, both overall and pre/post implementation of the Healthy, Hunger-Free Kids Act.

Design: Multi-year (2010-2013) cross-sectional study using pre- and post-meal digital photographs of students' school lunch trays to estimate fruit and vegetable availability and consumption. Fruit and vegetable items were categorized for factors suspected to impact waste: prior farm to school years, placement (main menu, salad bar), procurement (local, conventional), preparation (cooked, raw) and meal component (entrée, side, topping). Analyses to assess within-category differences in waste volume were performed using a Tobit model.

Setting: Wisconsin elementary schools participating in farm to school programmes, USA.

Subjects: Children in third to fifth grade.

Results: Many within-factor differences were detected overall and/or across time. Cooked fruits were wasted less than raw, while cooked vegetables were wasted more than raw. Where identified, locally sourced items were wasted more than conventionally sourced $(+0 \cdot 1$ cups, $P<0 \cdot 0001)$ and salad bar items more than main menu items $(+0.01$ cups, $P<0.0001)$. Increasing prior farm to school years decreased waste $(-0.02$ cups, $P<0.0001)$. Items previously tried were wasted at the same volume whether reported as liked or not. New school lunch meal pattern requirement implementation did not uniformly impact fruit and vegetable waste across all categories and there was no change in waste for seven of fifteen assessed categories.

Conclusions: Many factors impact elementary students' school lunch waste. These factors may be helpful for school food-service authorities to consider when planning school menus.
\end{abstract}

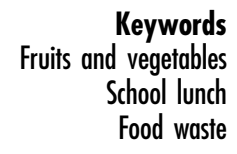

The prevalence of obesity among children and adolescents has grown over the past three decades, recently reaching $17 \%^{(1-3)}$, over half of the adult obesity prevalence rate, which stood at nearly $36 \%$ in $2009-2010^{(3)}$. Obesity and related co-morbidities have public health as well as economic implications ${ }^{(4,5)}$. Because of this high prevalence, public health personnel and medical professionals emphasize the importance of consuming a healthy diet $^{(6)}$. Few children meet consumption recommendations for fruit and vegetables $(\mathrm{F} \& \mathrm{~V})^{(7)}$. One strategy hypothesized to help achieve this is improving the quality of school meals. These efforts include promoting increased consumption of low-energy-density foods such as F\&V which, on the basis of high water and fibre content, alongside their low fat content, collectively yield larger bulk and low energy density. Although the positive effects of low-energy-dense food have been demonstrated in adults $^{(8)}$, the data are somewhat inconsistent, particularly among children ${ }^{(9-11)}$.

While many factors influence dietary preferences and habits, encouraging children to consume recommended amounts of $\mathrm{F} \& \mathrm{~V}$ is often part of programming conducted in schools ${ }^{(12-18)}$. Schools are common intervention sites for studies in children due to their large, representative populations ${ }^{(19)}$. Schools have the potential to reach across multiple levels of the socio-ecological model $^{(20)}$ : individual, interpersonal, organizational and community touchpoints are all feasible within school-based 
interventions. One specific US programme, Farm to School (F2S), aims to increase children's F\&V consumption through nutrition and agriculture education in the classroom and with experiential learning activities, and simultaneously to support local farmers by promoting local food purchasing ${ }^{(21)}$. More importantly, it is one of the specific strategies cited by the Centers for Disease Control and Prevention as having potential to increase healthy food access and F\&V consumption $^{(22)}$. F2S programme implementation varies by school, generally growing out of grass-roots efforts to enhance education by building on the strengths and resources available to a specific community ${ }^{(21,23)}$.

The potential for schools to impact children's dietary choices has been further enhanced through passage of the Healthy, Hunger-Free Kids Act (HHFKA), which requires increased $\mathrm{F} \& \mathrm{~V}$ on students' school lunch trays specifically, one-half of a cup of fruit and three-quarters of a cup of vegetables are required for meal pattern compliance, whereas the old school lunch programme required students to take only one serving of a fruit or a vegetable $^{(24)}$. This law does not directly address strategies to improve consumption, however, leading to questions of whether increased F\&V availability for children translates into increased intake or increased waste. It is possible that increased F\&V availability will lead to financial losses for school food-service authorities due to food waste certainly an important consideration in the face of tight budgets. Finding ways to serve the required F\&V that will appeal to students such that they eat them, thereby not wasting the increased federal school meal reimbursement amount, is important. A recent report, however, indicated that US students generally are accepting of the new meal standards and that there was no perceived increased change in the amount of food being discarded, particularly in elementary schools ${ }^{(25)}$. Despite this evidence, a number of media portray the new meal standards as leading students to reject the meal, thus leading to greater waste $^{(26,27)}$.

Few previous studies have investigated waste of $F \& V$ items specifically; most focus instead on consumption ${ }^{(16,28-30)}$. Two groups assessed plate waste according to broad factors (food groups) in children, finding that both fruits and vegetables were wasted at high percentages ${ }^{(31,32)}$. Others have studied school lunch waste and associated costs, or factors associated with children's F\&V consumption $^{(33,34)}$. One study assessed the financial implications of food waste throughout the food chain ${ }^{(35)}$. The present study aims to evaluate, at the school level, factors, identifiable from either digital photographs or communication with food-service staff, associated with F\&V waste from student school lunch trays in schools involved in F2S programmes. Moreover, the study examines whether F2S, a nutrition intervention aimed at increasing $F \& V$ intake, can reduce $F \& V$ waste over time and whether implementation of the HHFKA changed waste at F2S sites.

\section{Experimental methods}

\section{Recruitment and design}

The present study was part of a larger evaluation of Wisconsin F2S programmes' effectiveness in improving students' dietary knowledge, attitudes and behaviours with respect to $\mathrm{F} \& \mathrm{~V}$ consumption; the complete evaluation protocol was reviewed by the University of WisconsinMadison Institutional Review Board and determined to be exempt. This project comprised secondary analysis of lunch trays from third, fourth and fifth graders in eleven schools in Wisconsin, a Midwestern state with a strong agriculture economy outside two major metropolitan areas. Data were collected in autumn 2010 (eight schools), spring 2011 (eight schools), autumn 2011 (six schools), spring 2012 (three schools) and spring 2013 (seven schools). Participation varied because grant funding changed during this period, thus impacting which schools participated. A total of 320 third-grade, 1028 fourth-grade and 529 fifth-grade students were enrolled in the schools at the times of data collection, but student identity was not connected to tray photographs. Each period of data collection contributed to the current multi-year crosssectional observational study.

\section{Data collection}

At each data collection time, digital photographs were taken at lunchtime for four days at each school, which were usually consecutive days, but all schools completed this within a two-week period. Data collection (taking photographs of lunch trays) was performed by AmeriCorps members implementing F2S programming at the participating schools and recruited volunteers (autumn 2010 through spring 2013, eight schools) or by staff from local coalitions working to implement F2S at the school and recruited volunteers (spring 2013 only, three schools). These groups varied due to differences in grant funding as mentioned above for school participation. AmeriCorps members received training in person (September 2010, 2011) or by telephone conference (spring 2012) and were invited to a training webinar prepared for coalition staff (March 2013; led by the evaluation coordinating centre with AmeriCorps members experienced in the data collection protocol). AmeriCorps members and coalition staff, in turn, recruited and trained their respective volunteers. In addition, all sites received a written protocol and ongoing technical assistance by telephone and email upon request from the evaluation coordinating centre staff. Efforts were made to capture photographs of every lunch tray from third, fourth and/or fifth graders (specific grades varied by school; school lunch participation rates varied by school). Trays were numbered to permit before- and after-meal pairing for side-by-side comparison. Grade was identifiable from tray numbers if multiple grades within a school had a shared lunchtime, with the exception of three schools in autumn 2010. Photographs and menus were 
uploaded and transmitted to the coordinating centre for analysis by the coordinating staff. The coordinating staff included the same evaluation director and analyst for the duration of the project, and a rotating staff member responsible for matching pre- and post-meal numbered trays. The number of trays from each school (each day) varied by the number of children in attendance and taking school lunch, as well as by exclusions of any incomplete data points (such as missing or blurry photographs) applied during analysis, as further described elsewhere ${ }^{(36)}$. In total, 7117 trays were analysed.

\section{Data analysis}

The same analyst visually examined each pair of before-/ after-meal tray photographs and recorded the date, tray number, food items, serving sizes and percentage remaining for each item on each tray. School food-service staff submitted typical serving sizes of F\&V items via informal questionnaire, although some items were not served in standard sizes, such as items that were available from the salad bar rather than those that were part of the main lunch. Serving sizes were noted in cups based on the provided serving sizes and visual estimations from the photographs using the tray dimensions for reference; percentage remaining was estimated in $25 \%$ increments $(0,25,50,75$ and $100 \%)$ of the served/selected portion. Amounts wasted were calculated as serving size multiplied by percentage remaining. The analyst periodically reviewed a selection of photographs and their item amount assessments to verify intra-rater reliability, although no formal statistics were performed. Others have found visual assessments of foods based on digital photographs to be reliable ${ }^{(37-40)}$.

F\&V items were excluded if a tray lacked either a before- or after-meal photograph, if the photograph quality was too poor (unfocused) to ascertain the volume data or if the F\&V item was considered 'masked' (e.g. broccoli in heavy cheese sauce, dessert-style fruit, jellied cranberry sauce or gelatin-based fruit dishes; see online supplementary material, Supplementary Table 1 for a fuller list of items initially included in this list as well as those excluded from the final analysis). In total, 1132 total F\&V items were excluded from analysis. Following these exclusions, $11420 \mathrm{~F} \& \mathrm{~V}$ items remained for waste analysis. $\mathrm{F} \& \mathrm{~V}$ item waste volume (cups) and percentage waste were calculated from the original visual-analysis values of serving size and percentage eaten.

Each item was categorized as fully as possible for the following variables: (i) F2S-related variables, i.e. prior years of programming in a school, service line placement (main menu item or salad bar; where known) and purchase source (local or conventional); and (ii) item-specific characteristics, i.e. item type (fruit or vegetable), preparation method (cooked/canned $v$. fresh/raw) and menu component type (entrée, side dish or topping (e.g. tomato slice or lettuce on a sandwich)). Items' factor-level characterizations were assigned by first using information gleaned directly from the photographs, then verified by examining school lunch menus; this mostly yielded factor information for preparation and item types, service line placement and menu component. Additional follow-up with food-service staff or evaluation site personnel (who had established relationships with school food-service staff) was conducted by telephone or email to collect information about food procurement sourcing.

\section{Statistical analysis}

All statistical analyses were performed using the statistical software package SAS version $9 \cdot 2$ with a significance level of $P=0 \cdot 05$. Descriptive statistics were performed to obtain the mean and standard deviation for each factor overall and by semester. Due to non-normal distributions, statistical significance was determined using the Tobit model within non-linear mixed modelling (in SAS, the NLMIXED procedure), which is useful for data sets with differing distributions, in particular data where a high proportion of outcome data is ' 0 ' (in this case, the amount of waste for a given item, observed in approximately $55 \%$ of item observations) ${ }^{(41)}$. In tables, sample sizes represent individual F\&V items, rather than the number of trays or students. All models were adjusted for students' grade to account for presumed differences in body sizes (growing children) and their accompanying nutritional/energy needs because the Pearson correlation coefficient between cups wasted and grade trended towards significance $(P=0 \cdot 11, r=0 \cdot 015)$. In addition, models included school as a random-effect term to account for variations in school cultures and programme implementation. Relationships with waste were investigated according to the factors described above. Grade- and school-adjusted Tobit modelling was also used to assess differences in F\&V item waste before (spring 2011) and after (spring 2013) implementation of the HHFKA.

\section{Results}

Table 1 shows overall student and site characteristics. For the first academic year (autumn 2010, spring 2011), a total of 845 students could have participated based on the number of students in the participating grades from participating schools. This would have yielded 6760 unique trays had $100 \%$ of students participated in the National School Lunch Program (NSLP) and all photographs been accepted. Instead, NSLP participation in the first academic year averaged $73 \%{ }^{(42)}$, which would have yielded 4959 trays; we obtained photographs of 4462 trays or $90 \%$ of those possible based on NSLP participation. Across all data collection times, we obtained a total of 7117 trays from 1877 students. Based on NSLP participation we would have expected 7508 trays and thus we obtained $95 \%$ of expected trays. Seventeen per cent of trays came from third graders, $43 \%$ from fourth graders and $21 \%$ from fifth 
graders. Due to common lunchtimes, an additional $4 \%$ and $14 \%$ were indistinguishable between third and fourth grades and fourth and fifth grades, respectively. Overall, $54 \%$ of students in participating grades within participating schools were male and $79 \%$ were Caucasian; however, it is not known whether the students who ate from

Table 1 School-level characteristics of students in elementary schools participating in F2S programmes, Wisconsin, USA, 2010-2013

\begin{tabular}{|c|c|}
\hline Characteristic & $n$ or $\%$ \\
\hline Items $(n)$ & 11420 \\
\hline Trays $(n)$ & 7117 \\
\hline Third grade $(\%)^{*}$ & $17 \cdot 3$ \\
\hline Third grade + fourth grade (indistinguishable) $(\%) \dagger$ & $3 \cdot 7$ \\
\hline Fourth grade $(\%)^{*}$ & $43 \cdot 3$ \\
\hline Fourth grade + fifth grade (indistinguishable) $(\%) \dagger$ & $14 \cdot 2$ \\
\hline Fifth grade $(\%)^{*}$ & 21.4 \\
\hline \multicolumn{2}{|l|}{ School-level characteristics } \\
\hline Students $(n) \ddagger$ & 1877 \\
\hline Sex $(\%$ male $) \ddagger$ & $54 \cdot 0$ \\
\hline \multicolumn{2}{|l|}{ Ethnicity (\%)‡ } \\
\hline Caucasian & $78 \cdot 7$ \\
\hline Native American & $12 \cdot 0$ \\
\hline African-American & $2 \cdot 7$ \\
\hline Asian-American & $2 \cdot 9$ \\
\hline Hispanic & $2 \cdot 8$ \\
\hline Other & 0.9 \\
\hline \multicolumn{2}{|l|}{ Prior years in F2S (\%)‡ } \\
\hline 0 & $18 \cdot 0$ \\
\hline 1 & $22 \cdot 9$ \\
\hline 2 & $26 \cdot 8$ \\
\hline 3 & 18.4 \\
\hline 4 & 8.9 \\
\hline 5 & $5 \cdot 1$ \\
\hline Students eligible for FRPL (\%)§ & $49 \cdot 1$ \\
\hline Students participating in NSLP (\%)§ & $65 \cdot 7$ \\
\hline
\end{tabular}

F2S, Farm to School; FRPL, free/reduced-price lunch; NSLP, National School Lunch Program.

*Based on students known to have at least one tray in the data at collection time (i.e. where tray number matched de-identified student evaluation ID).

tIn autumn 2010 there were three schools, and in spring 2011 there was one school, where two grades ate lunch at the same time and it was not possible to separate the grades.

¥Based on total school-level data. Actual participation may have varied slightly, but individual-level data are not reported.

$\S B$ ased on information available at the district level through the Department of Public Instruction ${ }^{(42)}$. the trays represented in the study exactly represent these overall proportions. Schools' prior years of F2S programming ranged from 0 to 5 years; $18 \%$ of trays came from schools with no prior programming at the start of the school year in which the data collection took place, $23 \%$, $27 \%, 18 \%, 9 \%$ and $5 \%$ came from schools with one, two, three, four and five prior years, respectively.

The mean serving size as all F\&V items appeared on students' trays was $0 \cdot 38$ (SD 0.26) cups (Table 2). From this, 0.27 ( $\mathrm{SD} 0 \cdot 23$ ) cups disappeared (and were assumed to have been consumed), leaving a mean of 0.11 (SD 0.19) cups uneaten or wasted ( $27 \%$ (SD $36 \%)$ ). F\&V serving size and consumption were both significantly correlated with grade $(P \leq 0.02)$ and $\mathrm{F} \& \mathrm{~V}$ cups wasted weakly approached a significant correlation with grade $(P=0 \cdot 11)$; however, for all three of these variables, grade explained less than $1 \%$ of the variance.

\section{Farm to School-related factors}

When examining $F \& V$ waste according to prior years of F2S programming, there were no significant differences between groups after adjusting for grade and school (Table 3). The percentage of F\&V wasted tended to be slightly lower among students with three prior years of programming $(P=0 \cdot 06)$, while it tended to be slightly higher among students with four prior programme years $(P=0.09)$. The variance within each prior-year group varied substantially (see online supplementary material, Supplementary Fig. 1).

Two frequent components for a F2S programme include: (i) implementation of a salad bar in the school lunch programme; and (ii) purchasing foods from local farmers for use in school meals. Therefore, we examined waste outcomes (separately) according to items' classifications as (i) appearing on the main menu $v$. on the salad bar and (ii) being identified by school food-service staff as being purchased locally $v$. conventionally (Table 4). Overall, items from the salad bar were wasted at a higher amount than items from the main menu (+0.03 cups, $P=0.007)$. Following implementation of the HHFKA, there

Table 2 Waste of fruits and vegetables according to grade; elementary schools participating in F2S programmes, Wisconsin, USA, 2010-2013

\begin{tabular}{|c|c|c|c|c|c|c|c|c|c|}
\hline \multirow[b]{2}{*}{ Characteristic } & \multirow[b]{2}{*}{ Items $(n)$} & \multicolumn{2}{|c|}{ Serving size (cups) } & \multicolumn{2}{|c|}{ Cups eaten } & \multicolumn{2}{|c|}{ Percentage wasted } & \multicolumn{2}{|c|}{ Cups wasted } \\
\hline & & Mean & SD & Mean & SD & Mean & SD & Mean & SD \\
\hline All & 11420 & 0.38 & 0.26 & 0.27 & 0.23 & 27 & 36 & 0.11 & 0.19 \\
\hline \multicolumn{10}{|l|}{ Grade } \\
\hline Third & 2055 & 0.35 & 0.21 & 0.26 & 0.21 & 27 & 37 & $0 \cdot 10$ & 0.17 \\
\hline Third + fourth* & 597 & 0.32 & 0.22 & 0.24 & 0.21 & 22 & 34 & 0.07 & 0.14 \\
\hline Fourth & 5028 & 0.39 & 0.27 & 0.28 & 0.24 & 28 & 37 & $0 \cdot 12$ & 0.20 \\
\hline Fourth + fifth* & 993 & 0.40 & 0.29 & 0.27 & 0.23 & 27 & 34 & 0.13 & 0.21 \\
\hline Fifth & 2746 & 0.37 & 0.27 & 0.27 & 0.25 & 26 & 35 & $0 \cdot 10$ & 0.18 \\
\hline Pearson correlation coefficient, column $v$. grade & & \multirow{2}{*}{\multicolumn{2}{|c|}{$\begin{array}{l}0.030 \\
0.001\end{array}$}} & \multicolumn{2}{|c|}{0.022} & \multicolumn{2}{|c|}{0.001} & \multirow{2}{*}{\multicolumn{2}{|c|}{$\begin{array}{l}0.015 \\
0.11\end{array}$}} \\
\hline$P$ (correlation) & & & & 0. & & & & & \\
\hline
\end{tabular}

F2S, Farm to School.

*In autumn 2010.there were three schools, and in spring 2011 there was one school, where two grades ate lunch at the same time and it was not possible to separate the grades. 
Table 3 Waste of fruits and vegetables according to prior years of F2S*, elementary schools participating in F2S programmes, Wisconsin, USA, 2010-2013

\begin{tabular}{|c|c|c|c|c|c|c|c|c|c|}
\hline \multirow[b]{3}{*}{ Characteristic } & \multirow[b]{3}{*}{ Items $(n)$} & & & \multirow{2}{*}{\multicolumn{2}{|c|}{ Amount eaten (cups) }} & \multicolumn{4}{|c|}{ Amount wasted } \\
\hline & & \multicolumn{2}{|c|}{ Serving size (cups) } & & & \multicolumn{2}{|c|}{ Percentage } & \multicolumn{2}{|c|}{ Cups } \\
\hline & & Mean & SE & Mean & SE & Mean & SE & Mean & SE \\
\hline \multicolumn{10}{|c|}{ Prior F2S years } \\
\hline 0 & 2057 & 0.33 & 0.03 & 0.23 & 0.03 & 26 & 4 & 0.10 & 0.02 \\
\hline 1 & 2618 & 0.38 & 0.03 & 0.30 & 0.03 & 22 & 4 & 0.08 & 0.02 \\
\hline 2 & 3057 & 0.45 & 0.02 & 0.34 & 0.02 & 20 & 2 & $0 \cdot 10$ & 0.01 \\
\hline 3 & 2102 & 0.42 & 0.02 & 0.33 & 0.01 & $18 \dagger$ & 2 & 0.09 & 0.01 \\
\hline 4 & 1016 & 0.47 & 0.02 & 0.33 & 0.01 & $23 \dagger$ & 2 & 0.14 & 0.01 \\
\hline 5 & 578 & 0.50 & 0.37 & 0.43 & 0.03 & 12 & 4 & 0.07 & 0.02 \\
\hline
\end{tabular}

F2S, Farm to School.

*Means with their standard errors estimated using mixed modelling, adjusting for grade and treating school as a random effect.

†Mean values within a column followed by $\dagger$ indicates $0.05<P<0.10$ with respect to the other groups. Significance assessed by Tobit model, adjusted for grade, treating school as a random effect.

Table 4 Waste of fruits and vegetables according to F2S-related characteristics (service line placement, item source); elementary schools participating in F2S programmes, Wisconsin, USA, 2010-2013

\begin{tabular}{|c|c|c|c|c|c|c|c|c|c|c|}
\hline \multirow[b]{3}{*}{ Characteristic } & \multirow[b]{3}{*}{ Items $(n)$} & & & \multicolumn{7}{|c|}{ Waste (cups) } \\
\hline & & \multicolumn{2}{|c|}{ Serving size (cups) } & \multicolumn{2}{|c|}{ Overall } & \multicolumn{2}{|c|}{$\begin{array}{l}\text { Spring } 2011 \\
\text { (pre-HHFKA) }\end{array}$} & \multicolumn{2}{|c|}{$\begin{array}{l}\text { Spring } 2013 \\
\text { (post-HHFKA) }\end{array}$} & \multirow[b]{2}{*}{$P$, pre/post HHFKA } \\
\hline & & Mean & SD & Mean & SE & Mean & SE & Mean & SE & \\
\hline \multicolumn{11}{|c|}{ Service line placement } \\
\hline Main menu & 9608 & 0.38 & 0.25 & $0.09^{a}$ & 0.01 & 0.08 & 0.01 & 0.09 & 0.02 & 0.30 \\
\hline Salad bar & 1284 & 0.37 & 0.34 & $0.12^{b}$ & 0.02 & 0.21 & 0.03 & 0.24 & 0.08 & 0.99 \\
\hline \multicolumn{11}{|l|}{ Item source } \\
\hline Conventional & 6512 & 0.35 & 0.21 & $0.07^{\mathrm{C}}$ & 0.01 & -0.16 & 0.14 & -0.06 & 0.51 & 0.52 \\
\hline Local & 373 & 0.61 & 0.42 & $0.21^{d}$ & 0.02 & 0.04 & 0.01 & 0.09 & 0.02 & 0.33 \\
\hline
\end{tabular}

F2S, Farm to School; HHFKA, Healthy, Hunger-Free Kids Act.

a,b,c,d Mean values within a column (and within a factor) with unlike superscript letters were significantly different $(P<0.05)$. Significance assessed by Tobit model, adjusted for grade, including school as a random effect.

were no changes in average waste of foods from the main menu or from the salad bar.

Relatively few items were able to be definitively classified as locally or conventionally sourced due to incomplete reporting on this factor in two of the periods. Therefore, only autumn 2010, spring 2011 and spring 2013 items were included in the analysis and the results are considered pilot or preliminary data. Of these, an average of $5 \%$ of $\mathrm{F} \& \mathrm{~V}$ items were identified as locally sourced. Overall, locally sourced items were wasted at a much higher amount than conventionally sourced items $(+0 \cdot 14$ cups, $P<0 \cdot 0001$ ). Waste of both conventionally and locally sourced FV items did not differ after implementation of the HHFKA after adjusting for grade and school.

\section{Item-specific characteristics}

Fruits and vegetables were not wasted at different volumes after adjusting for grade and school $(P=0 \cdot 7$; Table 5). Waste volumes of fruits and vegetables did not change after implementation of the HHFKA.

Cooked and raw F\&V were wasted at different volumes (raw, +0.02 cups, $P<0 \cdot 0001$ ) and there were no changes in waste volume post-HHFKA implementation (Table 5). Despite the above finding that F\&V were not wasted differently from each other overall, fresh fruits were wasted at higher amounts than cooked fruits (+0.06 cups, $P<0.0001)$ while cooked vegetables were wasted at higher amounts than fresh ones $(+0.02$ cups, $P=0.0002)$. None of these subgroups changed following HHFKA implementation.

Another factor of interest, termed 'meal component,' indicated whether F\&V items appeared within a meal as part of an entrée (such as mashed potatoes under a chicken gravy, or a vegetable soup), as a side dish (such as cooked or raw vegetables) or as a topping (e.g. lettuce or tomato on a sandwich; Table 5). F\&V as entrée components were wasted at a higher amount than both side dishes and toppings (+0.14 cups, +0.09 cups and +0.03 cups, respectively, all $P<0 \cdot 0001$, after grade and school adjustments). None of these changed post-HHFKA implementation.

To provide greater detail for this cohort, we ranked items according to cups wasted (data not shown). This analysis included both regular menu items, which were generally served in fixed portions, and salad bar items, for 
Table 5 Waste of fruits and vegetables according to item characteristics; elementary schools participating in F2S programmes, Wisconsin, USA, 2010-2013

\begin{tabular}{|c|c|c|c|c|c|c|c|c|c|c|}
\hline \multirow[b]{3}{*}{ Characteristic } & \multirow[b]{3}{*}{ Items $(n)$} & & & \multicolumn{6}{|c|}{ Waste (cups) } & \multirow[b]{3}{*}{$P$, pre/post HHFKA } \\
\hline & & \multicolumn{2}{|c|}{ Serving size (cups) } & \multicolumn{2}{|c|}{ Overall } & \multicolumn{2}{|c|}{$\begin{array}{l}\text { Spring } 2011 \\
\text { (pre-HHFKA) }\end{array}$} & \multicolumn{2}{|c|}{$\begin{array}{c}\text { Spring } 2013 \\
\text { (post-HHFKA) }\end{array}$} & \\
\hline & & Mean & $\mathrm{SD}$ & Mean & $\mathrm{SE}$ & Mean & SE & Mean & SE & \\
\hline \multicolumn{11}{|l|}{ Item type } \\
\hline Fruit & 5253 & 0.41 & 0.24 & 0.11 & 0.00 & 0.11 & 0.01 & 0.13 & 0.02 & 0.87 \\
\hline Vegetable & 6174 & 0.35 & 0.27 & 0.08 & 0.02 & $0 \cdot 10$ & 0.01 & 0.10 & 0.03 & 0.35 \\
\hline \multicolumn{11}{|l|}{ Preparation type } \\
\hline Cooked & 5556 & 0.37 & 0.20 & $0.09^{a}$ & 0.00 & $0 \cdot 10$ & 0.01 & 0.10 & 0.02 & 0.85 \\
\hline Raw & 5203 & 0.37 & 0.31 & $0.11^{\mathrm{b}}$ & 0.02 & 0.11 & 0.01 & 0.14 & 0.04 & 0.77 \\
\hline Fruit, cooked & 2818 & 0.36 & 0.14 & $0.09^{c}$ & 0.01 & 0.08 & 0.01 & 0.06 & 0.02 & 0.08 \\
\hline Fruit, raw & 2225 & 0.46 & 0.32 & $0 \cdot 17^{d}$ & 0.02 & 0.17 & 0.02 & 0.15 & 0.56 & 0.36 \\
\hline Vegetable, cooked & 2739 & 0.38 & 0.24 & $0.07^{e}$ & 0.00 & 0.11 & 0.01 & 0.14 & 0.03 & 0.26 \\
\hline Vegetable, raw & 2977 & 0.30 & 0.28 & $0.05^{f}$ & 0.02 & 0.12 & 0.02 & 0.09 & 0.04 & 0.77 \\
\hline \multicolumn{11}{|l|}{ Meal component } \\
\hline Entrée & 718 & 0.57 & 0.36 & $0.14^{\mathrm{g}}$ & 0.01 & 0.12 & 0.10 & 0.19 & $0 \cdot 10$ & 0.31 \\
\hline Side dish & 9855 & 0.38 & 0.25 & $0.09^{\mathrm{h}}$ & 0.01 & 0.12 & 0.01 & 0.09 & 0.02 & 0.89 \\
\hline Topping & 854 & 0.23 & 0.19 & $0.03^{i}$ & 0.02 & -0.00 & 0.02 & 0.08 & 0.04 & 0.18 \\
\hline
\end{tabular}

HHFKA, Healthy, Hunger-Free Kids Act.

a,b,c,d,e,f,g,h,iMean values within a column (and within a characteristic) with unlike superscript letters were significantly different $(P<0.05)$. Significance assessed by Tobit model, adjusted for grade, including school as a random effect.

which portions taken varied. Portion sizes were collected from food-service staff for hot lunch menu items, and volume estimation for all $\mathrm{F} \& \mathrm{~V}$ items was conducted within the context of comparing known portion sizes with the salad bar items' plated amounts. Items with the least waste volume were hash browns, onion, green pepper, strawberries, tomatoes, kohlrabi, radishes, cucumbers, cauliflower and celery. Expressed as cups, the wasted volumes of these items were all less than one tablespoon (0.06 cups), but the percentage wasted varied from nearly $40 \%$ (tomatoes) to just 3\% (hash browns) because of differences in the amounts placed on the tray. Waste of high-waste $F \& V$ items ranged from just under one-eighth to just over one-quarter of a cup, but when expressed as a percentage, waste ranged from $20 \%$ (mashed potatoes) to just over $50 \%$ (asparagus). Items with the highest waste volume included mashed potatoes, steamed mixed vegetables, lettuce, roasted potatoes, coleslaw, romaine lettuce, asparagus, unsweetened applesauce, spinach (raw) and canned mixed vegetables. Most low-wastevolume items were self-serve items from the salad bar (exception: hash browns) and many high-waste-volume items were more fixed-portion items from the hot lunch menu (the following items came from both hot lunch and salad bar: lettuce, romaine lettuce, raw spinach).

\section{Discussion}

We found that a variety of characteristics used to describe specific F\&V items are associated with F\&V waste volume from students in schools participating in Wisconsin F2S programmes. Specifically, we found that F\&V waste varied according to preparation method (raw/cooked). F\&V items appearing on the salad bar were wasted more than items from the main menu, and entrée and side-dish F\&V items were wasted at higher volumes than toppings (e.g. on sandwiches, burritos). F\&V items sourced conventionally were wasted less than items sourced locally, although this finding is considered pilot data.

The differences in waste volume observed within factors in the present study are small, yielding further credit to our previous/separate findings relative to minimal changes in energy intake on the basis of F\&V energy intake ${ }^{(36,43)}$. The greatest within-factor difference observed was $0 \cdot 14$ cups, while the smallest was 0.02 cups. For perspective, 0.0625 cups is equal to one tablespoon, estimated at approximately two bites for a child. Again, these differences may seem nominal, but their application to the school scale yields potential for substantial financial meaning. It is important to note, however, that a 'clear your plate' mentality is not consistent with obesity prevention strategies that are based on children learning to stop eating when sated ${ }^{(44-46)}$. F2S programming focuses on encouraging a willingness to try new foods, even the unfamiliar, by cultivating experiential knowledge, and it fosters healthy eating by teaching nutritional concepts. F2S programming does not inherently focus on improving waste, although we did observe a slight decrease in waste commensurate with time in the programme.

If students do not consume what is served, the menu may not be achieving the goals of improving health. The importance of increased $\mathrm{F} \& \mathrm{~V}$ consumption for overall health benefits are well documented ${ }^{(8-10,47-49)}$. Thus, it is important for schools to find ways to encourage increased F\&V consumption and this is one goal of F2S programmes. 
In this regard, the findings that canned and other processed fruits were wasted less than fresh, and that fresh/ raw vegetables were wasted less than cooked, are important to consider when making choices to minimize waste while not using a 'clean your plate' approach. This factor alone could be transformative in school lunch programmes, since more fresh vegetables could potentially be served and yield less waste; however, the short shelf-life of fresh produce is a mitigating factor in the feasibility of such an approach. Among the few existing F\&V waste-related studies in children, other groups have variously found that fruits were wasted less than vegetables ${ }^{(32)}$ or that both fresh and canned fruits were wasted more than vegetables ${ }^{(31)}$.

These results may help guide school food-service directors as they make decisions about menu items and their preparation, service line placement and sourcing. Obviously, wasted food translates into financial loss for the food-service authority, an important consideration in a tight economy. As a specific example, replacing cooked mixed vegetables (an item wasted at high volume) with fresh tomatoes (an item with low waste volume) on just one day in a school where 200 students took school lunch, twenty cups (forty half-cup servings) of wasted vegetables could be avoided. The recent HHFKA implementation mandated that students have more F\&V on their lunch trays in order for meals to qualify as reimbursable ${ }^{(24)}$. The economic implications, although not addressed in the present study, have the potential to warrant consideration when applied at the national level.

Our small analysis of F\&V waste according to item sourcing, another F2S-related factor, showed higher waste of locally sourced than conventionally sourced items. In the context of F2S programming, this is another surprising result. Anecdotally, it may be related to food preparation or packaging: one food-service director reported that many students expect their food to arrive in packages and/or pre-cut forms, which is less likely to be the case for locally procured produce. It also may be due to serving size differences, as there was nearly a twofold difference in serving size ( 0.35 cups conventional $v \cdot 0.61$ cups local). Again in the context of F2S and the idea of a salad bar being an opportunity for students to apply knowledge of healthy dietary behaviours and improved attitudes towards eating $F \& V$, the finding of higher F\&V waste volume for salad bar items than for main menu items was surprising; however, it agrees with previous findings that the presence of a salad bar is not associated with greater F\&V consumption ${ }^{(28)}$. As suggested above, the presentation or preparation of salad bar items may be less familiar than items appearing on the main menu. In this case it is not likely due to differences in serving sizes, as main menu and salad bar F\&V items were not different.

The differences in meal-component factor F\&V waste were expected, given the differences in serving sizes. They do, however, suggest that 'toppings' items could be a valuable way to increase students' F\&V consumption, particularly vegetables, in school lunch. Although 'toppings' in the present study largely encompassed those for sandwiches or tacos, it could be extended to other ideas, such as create-your-own (veggie) pizza, baked potato bars or pasta bars.

We found neither increased nor decreased F\&V waste following HHFKA implementation. Others have found that the HHFKA has yielded healthier school meals ${ }^{(50,51)}$, but that children's school lunch consumption rarely meets NSLP standards ${ }^{(31)}$. To our knowledge, no other groups have assessed factors relating to $\mathrm{F} \& \mathrm{~V}$ waste to this degree, particularly in a pre-/post-HHFKA comparison, nor in a F2S setting. Importantly, however, we found no support for reports of increased food waste following implementation of the HHFKA in the popular media ${ }^{(26,27)}$.

The present study is limited by the inability to fully characterize each $\mathrm{F} \& \mathrm{~V}$ item according to each factor. It was also not possible to control for the different foods served (entrées or otherwise) due to the large number of different items included in the current analysis. Data collection times preceded the current secondary analysis (with the exception of May 2013) and it was not feasible to collect retrospective procurement records from schools at the time of the present study due to limited time on the part of school food-service and evaluation staff, and a lack of budget to provide any sort of participation incentive. Therefore, there were limitations to the degree to which we could delineate our data set with the selected factors as described above, notwithstanding the limitation of analysis at the school, rather than individual, level. Photographs of known F\&V volumes would have improved our visual assessments, but we believe that the analyst's training minimized this need and therefore we placed less burden on school districts. Additional factors may be helpful in further assessing F\&V waste factors that were not measured here, including consumption/waste of other lunch items, timing of the lunch period (total length of time, average time available after obtaining lunch tray, whether recess is before or after lunch, and what time the lunch period begins), whether an item was preferentially selected for tray placement or if the child was served the F\&V item without choice, and an individual's sex. Nevertheless, the present study offers substantial information in terms of both specific factors assessed and the time-sensitive assessment of waste before and after HHFKA implementation, as well as waste within the context of F2S programming.

Future studies would be strengthened by adding additional factors to the analysis, such as food factors or student-related factors (e.g. whether a student has previously tasted and/or liked a fruit or vegetable item), or testing the differences specifically of any of the factors in the present study by offering both options of one fruit or vegetable item within a factor in the same meal, such as offering both cooked and raw broccoli, or whole and cut apples. Additional research rigour could be added 
by weighing a sub-sample of trays. The question of economics in a school food-service setting should also be addressed by obtaining cost information for $\mathrm{F} \& \mathrm{~V}$ items assessed.

\section{Acknowledgements}

Financial support: This work was supported by the Centers for Disease Control and Prevention (grant numbers CDC CPPW 3U58DP001997 and CDC 1U58 DP003597); the US Department of Agriculture Hatch Act Formula Grant (grant number WISO1634); and the Corporation for National and Community Service Grant (grant number 06AFHWI0010031). The funders had no role in the design, analysis or writing of this article. Conflict of interest: None. Authorship: A.B.B.Y. and D.A.S. designed the Lunch Tray Photo Observation protocol (which was carried out by AmeriCorps members). A.B.B.Y. visually assessed all photographs. L.L.F. and A.B.B.Y. collaboratively conducted the data organization; A.B.B.Y. conducted the statistical analyses. All authors formulated the research questions, and wrote and edited the manuscript. Ethics of human subject participation: This project was reviewed by and approved as exempt by the University of Wisconsin-Madison Institutional Review Board.

\section{Supplementary material}

To view supplementary material for this article, please visit http://dx.doi.org/10.1017/S1368980015000385

\section{References}

1. Ogden CL, Carroll MD, Curtin LR et al. (2010) Prevalence of high body mass index in US children and adolescents, 2007-2008. JAMA 303, 242-249.

2. Ogden CL, Carroll MD, Kit B et al. (2012) Prevalence of obesity and trends in body mass index among US children and adolescents, 1999-2010. JAMA 307, 483-490.

3. Ogden CL, Carroll MD, Kit BK et al. (2012) Prevalence of Obesity in the United States, 2009-2010. NCHS Data Brief no. 82. http://www.cdc.gov/nchs/data/databriefs/db82.pdf (accessed December 2014).

4. Finkelstein EA \& Strombotne KL (2010) The economics of obesity. Am J Clin Nutr 91, issue 5, 1520S-1524S.

5. Allison DB, Zannolli R \& Narayan KM (1999) The direct health care costs of obesity in the United States. Am J Public Health 89, 1194-1199.

6. Gortmaker SL \& Story M (2012) Nutrition policy research that can lead to reduced childhood obesity in the US. $A m J$ Prev Med 43, 3 Suppl. 2, S149-S151.

7. Kimmons J, Gillespie C, Seymour J et al. (2009) Fruit and vegetable intake among adolescents and adults in the United States: percentage meeting individualized recommendations. Medscape J Med 11, 26-36.

8. Pérez-Escamilla R, Obbagy JE, Altman JM et al. (2012) Dietary energy density and body weight in adults and children: a systematic review. J Acad Nutr Diet 112, 671-684.

9. Tohill BC, Seymour J, Serdula M et al. (2004) What epidemiologic studies tell us about the relationship between fruit and vegetable consumption and body weight. Nutr Rev $\mathbf{6 2}$, 365-374.

10. Ledoux TA, Hingle MD \& Baranowski T (2011) Relationship of fruit and vegetable intake with adiposity: a systematic review. Obes Rev 12, e143-e150.

11. Bayer O, Nehring I, Bolte G et al. (2014) Fruit and vegetable consumption and BMI change in primary school-age children: a cohort study. Eur J Clin Nutr 68, 265-270.

12. Tuuri G, Zanovec M, Silverman L et al. (2009) 'Smart Bodies' school wellness program increased children's knowledge of healthy nutrition practices and self-efficacy to consume fruit and vegetables. Appetite 52, 445-451.

13. Wang MC, Rauzon S, Studer N et al. (2010) Exposure to a comprehensive school intervention increases vegetable consumption. J Adolesc Health 47, 74-82.

14. Jones M, Dailami N, Weitkamp E et al. (2012) Food sustainability education as a route to healthier eating: evaluation of a multi-component school programme in English primary schools. Health Educ Res 27, 448-458.

15. Parmer SM, Salisbury-Glennon J, Shannon D et al. (2009) School gardens: an experiential learning approach for a nutrition education program to increase fruit and vegetable knowledge, preference, and consumption among secondgrade students. J Nutr Educ Behav 41, 212-217.

16. Hoffman JA, Franko DL, Thompson DR et al. (2010) Longitudinal behavioral effects of a school-based fruit and vegetable promotion program. J Pediatr Psychol 35, 61-71.

17. Siega-Riz AM, El Ghormli L, Mobley C et al. (2011) The effects of the HEALTHY study intervention on middle school student dietary intakes. Int J Behav Nutr Phys Act 8, 7.

18. Reinaerts E, Crutzen R, Candel $M$ et al. (2008) Increasing fruit and vegetable intake among children: comparing longterm effects of a free distribution and a multicomponent program. Health Educ Res 23, 987-996.

19. Story M, Kaphingst KM \& French S (2006) The role of schools in obesity prevention. Future Child 16, 109-142.

20. McLeroy KR, Bibeau D, Steckler A et al. (1988) An ecological perspective on health promotion programs. Health Educ Q 15, 351-377.

21. National Farm to School Network (2013) The Benefits of Farm to School. http://www.farmtoschool.org (accessed May 2014).

22. Centers for Disease Control and Prevention (2009) Recommended community strategies and measurements to prevent obesity in the United States. MMWR Recomm Rep 58, 1-26.

23. Feenstra G \& Ohmart J (2012) The evolution of the School Food and Farm to School Movement in the United States: connecting childhood health, farms, and communities. Child Obes 8, 280-289.

24. 111th Congress (2010) Public Law No. 111-296, 124 Stat. 3183. Healthy, Hunger-Free Kids Act of 2010. http://www.gpo. gov/fdsys/pkg/PLAW-111publ296/pdf/PLAW-111publ296.pdf (accessed December 2014).

25. Turner L \& Chaloupka FJ (2014) Perceived reactions of elementary school students to changes in school lunches after implementation of the United States Department of Agriculture's new meals standards: minimal backlash, but rural and socioeconomic disparities exist. Child Obes 10, 349-356.

26. Kasperowicz P (2014) Michelle Obama's school lunch rules leading to healthy, hunger-free trash cans. The Blaze, 14 October. http://www.theblaze.com/blog/2014/10/14/ michelle-obamas-school-lunch-rules-leading-to-healthy-hungerfree-trash-cans-2/ (accessed December 2014).

27. Bonvillian C (2014) What's in that lunch? Students in Huntsville, Madison still leery of healthier school meals. http://www.al.com/news/huntsville/index.ssf/2014/10/school_ lunch_series_kickoff.html (accessed December 2014).

28. Adams MA, Pelletier RL, Zive MM et al. (2005) Salad bars and fruit and vegetable consumption in elementary schools: a plate waste study. J Am Diet Assoc 105, 1789-1792. 
29. Hakim SM \& Meissen G (2013) Increasing consumption of fruits and vegetables in the school cafeteria: the influence of active choice. J Health Care Poor Underserved 24, 145-157.

30. Hoffman JA, Thompson DR, Franko DL et al. (2012) Decaying behavioral effects in a randomized, multi-year fruit and vegetable intake intervention. Prev Med 52, 370-375.

31. Smith SL \& Cunningham-Sabo L (2014) Food choice, plate waste and nutrient intake of elementary- and middle-school students participating in the US National School Lunch Program. Public Health Nutr 17, 1255-1263.

32. Nicklas T, Liu Y, Stuff J et al. (2013) Characterizing lunch meals served and consumed by pre-school children in Head Start. Public Health Nutr 16, 2169-2177.

33. Cohen JFW, Richardson S, Austin SB et al. (2013) School lunch waste among middle school students: nutrients consumed and costs. Am J Prev Med 44, 114-121.

34. Krølner R, Rasmussen M, Brug J et al. (2011) Determinants of fruit and vegetable consumption among children and adolescents: a review of the literature. Part II: qualitative studies. Int J Behav Nutr Phys Act 8, 112.

35. Nahman A \& de Lange W (2013) Costs of food waste along the value chain: evidence from South Africa. Waste Manag 33, 2493-2500.

36. Bontrager Yoder AB, Liebhart JL, McCarty DJ et al. (2014) Farm to elementary school programming increases access to fruits and vegetables and increases their consumption among those with low intake. I Nutr Educ Behav 46 341-349.

37. Swanson M (2008) Digital photography as a tool to measure school cafeteria consumption. J Sch Health 78, 432-437.

38. Martin CK, Nicklas T, Gunturk B et al. (2014) Measuring food intake with digital photography. J Hum Nutr Diet 27, 72-81.

39. Williamson DA, Allen R, Martin PD et al. (2003) Comparison of digital photography to weighed and visual estimation of portion sizes. J Am Diet Assoc 103, 1139-1145.

40. Martins Rodrigues AG \& da Costa Proenca RP (2011) Use of food images for evaluating food intake. Rev Nutr - Braz J Nutr 24, 765-776
41. Tobin J (1958) Estimation of relationships for limited dependent variables. Econometrica 26, 24-36.

42. Wisconsin Department of Public Instruction (2014) Program Statistics. http://fns.dpi.wi.gov/fns_progstat (accessed February 2014).

43. Bontrager Yoder AB \& Schoeller DA (2014) Fruits and vegetables displace, but do not decrease, total energy in school lunches. Child Obes 10, 357-364.

44. Carnell S \& Wardle J (2008) Appetitive traits and child obesity: measurement, origins and implications for intervention. Proc Nutr Soc 67, 343-355.

45. Ho M, Gow M, Halim J et al. (2013) Effect of a prescriptive dietary intervention on psychological dimensions of eating behavior in obese adolescents. Int J Behav Nutr Phys Act 10, 119.

46. Dattilo AM, Birch L, Krebs NF et al. (2012) Need for early interventions in the prevention of pediatric overweight: a review and upcoming directions. J Obes 2012, 123023.

47. Vernarelli JA, Mitchell DC, Hartman TJ et al. (2011) Dietary energy density is associated with body weight status and vegetable intake in US children. J Nutr 141, 2204-2210.

48. Angelopoulos PD, Milionis HJ, Grammatikaki E et al. (2009) Changes in BMI and blood pressure after a school based intervention: the CHILDREN study. Eur J Public Health 19 , 319-325.

49. Prentice RL, Willett WC, Greenwald P et al. (2004) Nutrition and physical activity and chronic disease prevention: research strategies and recommendations. J Natl Cancer Inst 96, 1276-1287.

50. Baxter SD, Paxton-Aiken AE, Tebbs JM et al. (2012) Secondary analyses of data from 4 studies with fourth-grade children show that sex, race, amounts eaten of standardized portions, and energy content given in trades explain the positive relationship between body mass index and energy intake at school-prov. Nutr Res 32, 659-668.

51. Ohri-Vachaspati P, Turner L \& Chaloupka FJ (2013) Elementary school participation in the United States Department of Agriculture's Team Nutrition program is associated with more healthful school lunches. J Nutr Educ Behav 45, 733-738. 